\title{
Modeling of Shale Gas Adsorption and its Influence on Phase Equilibrium
}

\author{
Sandoval Lemus, Diego Rolando; Yan, Wei; Michelsen, Michael Locht; Stenby, Erling Halfdan
}

Published in:

Industrial \& Engineering Chemistry Research

Link to article, DOI:

10.1021/acs.iecr.7b04144

Publication date:

2018

Document Version

Peer reviewed version

Link back to DTU Orbit

Citation (APA):

Sandoval Lemus, D. R., Yan, W., Michelsen, M. L., \& Stenby, E. H. (2018). Modeling of Shale Gas Adsorption and its Influence on Phase Equilibrium. Industrial \& Engineering Chemistry Research, 57, 5736-5747. https://doi.org/10.1021/acs.iecr.7b04144

\section{General rights}

Copyright and moral rights for the publications made accessible in the public portal are retained by the authors and/or other copyright owners and it is a condition of accessing publications that users recognise and abide by the legal requirements associated with these rights.

- Users may download and print one copy of any publication from the public portal for the purpose of private study or research.

- You may not further distribute the material or use it for any profit-making activity or commercial gain

- You may freely distribute the URL identifying the publication in the public portal 


\title{
Modeling of Shale Gas Adsorption and its Influence on Phase Equilibrium
}

\author{
Diego R. Sandoval, ${ }^{\dagger}$ Wei Yan, ${ }^{* \dagger}{ }^{\dagger}$ Michael L. Michelsen, ${ }^{\dagger}$ and Erling H. Stenby ${ }^{\dagger}$ \\ $\dagger$ Center for Energy Resources Engineering (CERE), Department of Chemistry, Technical \\ University of Denmark, Lyngby 2800 \\ $\ddagger$ Center for Energy Resources Engineering (CERE), Department of Chemical Engineering, \\ Technical University of Denmark, Lyngby 2800 \\ E-mail: *weya@kemi.dtu.dk
}

\begin{abstract}
Natural gas and oil produced from shale accounts for a significant portion in the global production. Due to the large surface area and high organic content in shale formations, adsorption plays a major role in the storage of the hydrocarbons within the rock and their phase equilibrium. This study provides a comparison of several engineering models for gas adsorption in shale based on the recent literature data for pure and binary gases. For pure components, Langmuir, the modified Toth-Langmuir, and the Multicomponent Potential Theory of Adsorption using Dubinin-Radushkevich potential (MPTA-DRA) were compared. The three models show similar deviations lower than 10\%. For binary gases, Multicomponent Langmuir (ML), Ideal Adsorbed Solution Theory (IAST) and MPTA were evaluated, where MPTA shows the lowest deviation with $17.9 \%$. Additionally, we presented an analysis of the phase envelope shift under the influence of the capillary pressure and the adsorption film. ML and IAST were used to calculate the adsorption amount whereas MPTA was used to generate artificial adsorption data over large temperature range and for other homologous
\end{abstract}


hydrocarbons to estimate the ML and IAST parameters. The adsorption film thickness was considered in the calculation of the effective capillary radius and the corresponding capillary pressure. The combined effects modify the saturation pressure in the whole temperature range except at the critical point. The biggest impact was found on the bubble point branch away from the critical point where the interfacial tension of the system is more pronounced.

\section{Introduction}

Oil and gas production from shale has received a lot of attention in the last decade. Today, shale is one of the most attractive and abundant unconventional energy resource. For instance, it is estimated that about $60 \%$ of total U.S. dry natural gas production in 2016 came from shale and tight reservoirs. ${ }^{1}$ This has resulted in a lot of research towards a better understanding of the physical and chemical processes involved in shale production. One of these processes is adsorption of hydrocarbons and $\mathrm{CO}_{2}$ inside shale. Natural gas inside shale is stored in three different forms: as free gas inside the macro- and meso-pores; as adsorbed gas inside organic and inorganic micro-pores; and as dissolved gas in oil and water. ${ }^{2}$ Owing to the high percentage of micropores inside the shale matrix, the adsorbed hydrocarbons become an important portion of the total oil and gas in place. Not only can the adsorbed amount inside the reservoir be considerably high, but also can the adsorption process play an important role in the phase equilibrium close to the saturation point as demonstrated by Shapiro and Stenby ${ }^{3}$ and Dong et al. ${ }^{4}$ An accurate description of adsorption at the underground conditions is therefore necessary for both estimation of the hydrocarbons-in-place and simulation of the production process.

Shale is a heterogeneous mixture of organic and inorganic matter which results in a wide variation of surface chemistry and pore shapes/sizes. In some shales the micro-pores responsible for adsorption are associated with mineral grains, ${ }^{5}$ however, for the great majority

of shales the small size micro-pores are located in organic patches, representing the main 
source of adsorbed gas. This suggests that the organic content in shale might determine the adsorption capacity. ${ }^{2}$ The heterogeneity of shale as an adsorbent makes adsorption very hard to study. In addition, its experimental measurements at high pressures (up to 250 bar) and temperatures (up to $338 \mathrm{~K}$ ) restricted by low uptakes have shown to be very challenging as presented in an inter-laboratory comparison by Gasparik et al. ${ }^{6}$ The inter-laboratory comparison reported significant discrepancies in the measurements and reproducibility between different laboratories. Recently, Holmes et al. ${ }^{7}$ investigated the shale preparation protocol and outgas procedures, revealing how outgas temperature can influence the pore capacity estimate. Their study also reflects the complexity in characterizing shale including its adsorption capacity. Several adsorption data inside shale for pure components such as methane, ethane, and $\mathrm{CO}_{2}$ can be found in literature. ${ }^{8-10}$ However, experimental data for binary systems are very limited. In order to study multicomponent adsorption inside shale, additional experimental data and reliable predictive adsorption models at high pressures and temperatures are required.

Many adsorption theories can be applied to study high pressure adsorption. Perhaps the simplest choice is the Langmuir model. When applying it to mixtures, we can use its empirical extension, the Multicomponent Langmuir (ML) model, or couple it with the Ideal Adsorbed Solution Theory (IAST), ${ }^{11}$ which provides a general framework to calculate mixture adsorption based on pure component adsorption isotherms. DFT methods are often employed to study the phase behavior in porous media including adsorption. For instance, Li et al. ${ }^{12}$ applied their engineering DFT method coupled with the Peng-Robinson EoS to pure components and their mixtures in mesopores as low as $2 \mathrm{~nm}$. Li et al. also reviewed previous studies using DFT and found that the DFT study of mixture adsorption is limited. There are however some simplified DFT theories which are extensively used in mixture adsorption modeling. One such model is the Simplified-Local-Density (SLD) model proposed by Rangarajan et al. ${ }^{13}$ It was initially proposed for pure component adsorption and extended to mixtures by Fitzgerald et al. ${ }^{14,15}$ The model was historically applied to gas adsorption 
on coal ${ }^{14-16}$ and recently also applied to shale. ${ }^{17,18}$ Another model called Multicomponent Potential Theory of Adsorption (MPTA) ${ }^{19}$ was proposed by Shapiro and Stenby based on the potential concept of Polanyi. ${ }^{20}$ MPTA is proposed for application to mixture adsorption. In a broad sense, it can be considered as a simplified DFT approach. The SLD approach and the MPTA approach were developed rather independently despite their similarities. The major difference between the two theories lies in the description of the fluid-fluid interactions: SLD accounts for the influence of the wall on the fluid-fluid energy term whereas MPTA describes the fluid-fluid interactions using the same EoS as for the bulk phase. As a result, the EoS used in SLD has to be modified by introducing EoS parameters dependent on the distance to the wall whereas that used in MPTA does not need to. It can be argued that SLD's consideration on the wall influence is a bit more sophisticated while MPTA is a bit more straightforward to implement because the existing thermodynamic module can be used directly.

Several validations and comparisons of adsorption models for different adsorbents can be found in the literature. ${ }^{21-23}$ MPTA has been applied to model adsorption of gas and liquid mixtures on absorbent like activated carbons and silica gels. ${ }^{22,24,25}$ Recently, Bartholdy et al. ${ }^{26}$ compared MPTA with Langmuir and IAST on prediction of multicomponent gas adsorption with emphasis on water and other polar gases and polar solids. In particular, for adsorption on organic-rich shales and coal, Clarkson and Hagshenas ${ }^{27}$ compared the simple Langmuir and Dubinin-Radushkevich (DR $)^{28}$ equations and a 2D-EoS model ${ }^{29}$ for pure component adsorption and provided a prediction for binary mixtures. They found that all models are able to fit the data well, with the 2D-EoS model slightly superior to the Langmuir and DR

The main objective of this study is to provide a comparison of different adsorption models for high-pressure adsorption data of pure components and binary mixtures in shale reported in recent literature. Three different models were tested for the fitting of pure component isotherms: the Langmuir, Toth-Langmuir, and MPTA using the Dubinin-Radushkevich- 
Astakhov (DRA) potential. For binary mixtures, three methods were compared: ML, IAST and MPTA-DRA. In addition to the model comparison, the influence of adsorption in phase equilibria is discussed. The phase envelopes of three binary mixtures involving capillary pressure and adsorption film are presented. The ML and IAST models were used to calculate the adsorption film thickness at each point along the phase envelope using adsorption data generated with MPTA. The effects of the adsorption film thickness on the phase behavior are discussed.

\section{Adsorption Models}

In this section, we briefly describe the adsorption models used in the comparison. This includes models for pure component fitting and multicomponent adsorption prediction.

\section{Multicomponent Langmuir (ML)}

The Langmuir model is a single layer adsorption model. ${ }^{30}$ It assumes that the adsorbent has a limited number of active sites to adsorb molecules, and the site can be either empty or occupied. The occupation of an active site by a molecule is associated to an equilibrium constant dependent on the heat of adsorption. Eq. 1 shows the Langmuir model for a pure component at high pressures:

$$
n^{a b s}=n^{\max }(T) \frac{b(T) f}{1+b(T) f}
$$

where $n^{a b s}$ is the absolute adsorbed amount, $n^{\max }(T)$ is the maximum adsorption capacity, $b(T)$ is the adsorption equilibrium constant, and $f$ is the fugacity of the fluid in contact with the adsorbed phase. The Langmuir model has been developed to calculate the absolute adsorbed amount or the actual number of molecules attached to the surface of the rock. From an experimental point of view, it is impossible to measure the absolute amount, it can only be estimated using indirect measurements of the adsorbed volume. Only tools 
like molecular simulations can give the absolute adsorbed amount in well defined geometries. The raw experimental measurements obtained by gravimetric or volumetric methods reported in literature correspond exclusively to excess amounts. ${ }^{31}$ The excess adsorption refers to the number of molecules in the nanopores in excess of the amount that would be present in the pore volume at the equilibrium density of the bulk gas. Figure 1 depicts the difference between excess adsorption and absolute adsorption $(\Delta n)$. This term is negligible at low pressures and therefore, the Langmuir model can be applied without any problems. Nonetheless, the difference between the absolute and excess adsorption at high pressure is too large to ignore. In such cases, the following modification to (Eq. 1) is needed:

$$
n^{e x c}=n^{\max }(T) \frac{b(T) f}{1+b(T) f}-\rho^{b} V_{a d s}
$$

where $\rho^{b}$ is the molar density of the bulk phase and $V_{a d s}$ is the volume occupied by the adsorbed phase. The second term on the right-hand side is the correction for the amount occupied by the bulk phase inside the adsorbed volume, it is also the link between absolute and excess amounts.

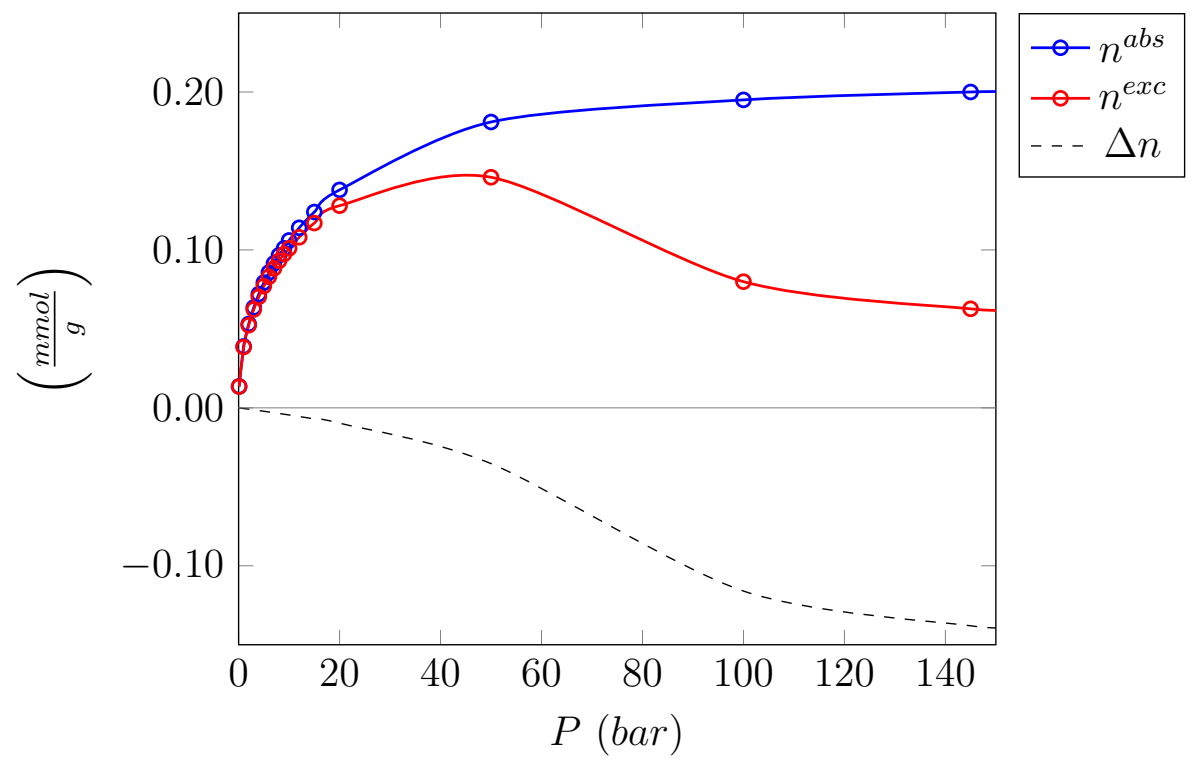

Figure 1: Common supercritical isotherm for $\mathrm{C}_{1}$ in shale at $323 \mathrm{~K}$. Data generated with MPTA 
In many cases, the adsorbed volume can be approximated by the micro-pore volume. However, if no information is given regarding the pore structure, $V_{a d s}$ should be treated as a separate fitting parameter of the adsorbent. This implies that the fitting of pure components belonging to the same rock sample should be done simultaneously.

The fitting of pure components is very crucial in adsorption thermodynamics. Calculation of the thermodynamic properties of the adsorbed phase and the prediction of multicomponent adsorption relies only on the pure component adsorption isotherms. The simplicity of the Langmuir model makes its extension to the multicomponent case quite straightforward. The Multicomponent Langmuir (ML) has the following form:

$$
n_{i}^{a b s}=n_{i}^{\max }(T) \frac{b_{i}(T) f_{i}}{1+\sum_{j=1}^{N c} b_{j}(T) f_{j}}
$$

where $N_{c}$ is the number of components in the mixture, and the subscript $\left.{ }_{i}{ }_{i}\right)$ refers to component $i$ in the mixture. Notice that the ML model is again exclusively for absolute adsorbed amounts. Therefore, in order to express the excess amounts, the same correction as before has to be applied

$$
n_{i}^{e x c}=n_{i}^{\max }(T) \frac{b_{i}(T) f_{i}}{1+\sum_{j=1}^{N c} b_{j}(T) f_{j}}-y_{i} \rho^{b} V_{a d s}
$$

where $y_{i}$ is the molar fraction of the gas phase, and $\rho^{b}$ the density of the gas mixture in contact with the adsorbed phase. The presented model (ML), from the computational point of view, is the simplest among the three multicomponent models tested here. Its implementation is straightforward since no numerical procedures are required for evaluating the properties of the adsorbed phase for the pure or for the multicomponent case. 


\section{Ideal Adsorbed Solution Theory (IAST)}

IAST was introduced by Myers and Prausnitz ${ }^{11}$ and is based on the concept of an ideal adsorbed solution using classical surface thermodynamics. It is a framework that only needs the experimental adsorption data for the pure components in order to predict adsorption of the mixture. The principal idea on which IAST is based is the definition of an ideal adsorbed solution in a similar form to that used for liquid solutions. A concept of partial pressures for the adsorbed components is used to calculate equilibrium between the adsorbed molecules and the fluid. The thermodynamic equations describing the adsorbed phase are analogous to those of real fluids and are based on three fundamental assumptions:

1. The adsorbent is thermodynamically stable, meaning that any isothermal change in the system (fluid + adsorbed phase) will not affect the internal energy of the adsorbent.

2. The area of the adsorbent is invariant for changes in the temperature and pressure of the system. Moreover, the area is the same for all the adsorbates.

3. The Gibbs dividing surface definition ${ }^{32}$ applies for the adsorbed phase. Thus, measurements procedures based on the excess adsorbed amount apply without any modifications for the calculation of the properties.

The two main differences of the thermodynamic equations for the adsorbed phase with respect to those of real fluids, are the replacement of the pressure $P$ for the spreading pressure $\pi$, and the replacement of the volume $V$ for the surface area $A$. Therefore, same as for real fluids, the change of internal energy $U$ and Gibbs energy $G$ as a function of the extensive $(S, A, n)$ and intensive variables $(T, \pi, \mu)$ of the system.

$$
\begin{gathered}
d U=T d S-\pi d A+\sum_{i} \mu_{i} d n_{i} \\
d G=-S d T-A d \pi+\sum_{i} n_{i} d \mu_{i}
\end{gathered}
$$


Following a procedure similar to that in solution thermodynamics, we can arrive at the equilibrium condition based on equal fugacities of the adsorbed phase and the bulk phase in contact,

$$
\left\{\begin{array}{l}
P y_{i} \varphi_{i}=f_{i}^{0}\left(\pi_{i}\right) x_{i} \\
\pi_{i}=\pi_{j} \\
\sum_{i} y_{i}=\sum_{i} x_{i}=1
\end{array} \quad i, j=1, \ldots, N_{c}\right.
$$

where for the bulk phase: $P$ is the pressure, $\varphi_{i}$ is the fugacity coefficient, $z_{i}^{b}$ is the molar composition; for the adsorbed phase: $f_{i}^{0}$ is the fugacity of the pure component $i$ alone at a spreading pressure $\pi, x_{i}^{a}$ is the molar composition, and $\gamma_{i}$ is the activity coefficient, which for the IAST framework is equal to one $(\gamma=1)$. For a detailed derivation, the reader is referred to. ${ }^{11}$

The fugacity dependence on the spreading pressure $f_{i}(\pi)$ is crucial to the solution of the system of equations in (Eq. 7). It is obtained by means of the Gibbs adsorption isotherm of the pure components:

$$
-A d \pi+n d \mu=0
$$

The integration of this equation and its following inversion gives us a relationship for the spreading pressure.

$$
\pi\left(f^{0}\right)=\frac{R T}{A} \int_{0}^{f^{0}} n(t) d \ln t \quad \rightarrow \quad f^{0}=f^{0}(\pi)
$$

At low pressures, it is possible to substitute $P^{0}$ for $f_{0}$, but formally the fugacity term is the one defined. In the IAST framework, in order to obtain the thermodynamic properties of the adsorbed phase, the surface excess amounts are used. ${ }^{24,33,34}$

At low pressures, where the absolute adsorbed amount coincides with the excess amount, the adsorption data can be fitted with Langmuir isotherms and (Eq. 9) can be integrated 
analytically.

$$
\pi\left(f^{0}\right)=\frac{R T}{A} n^{\max } \ln \left(1+b f_{0}\right)
$$

This relationship can be inverted to get the fugacity as an explicit function of the spreading pressure.

$$
f^{0}(\pi)=\frac{1}{b} \exp \left[\frac{1}{n^{\max }} \frac{A \pi}{R T}\right]-\frac{1}{b}
$$

It is worth noticing that $b$ and $n^{\max }$ are temperature dependent, therefore experimental data at different temperatures are necessary when calculations for a variety of temperatures are required. On the other hand, at high pressures, the normal Langmuir fitting is no longer satisfactory and models such as (Eq. 2) should be used to get the spreading pressure in (Eq. 9),

$$
\pi\left(f^{0}, T\right)=\frac{R T}{A} \int_{0}^{f^{0}}\left[n^{\max } \frac{b t}{1+b t}-\rho^{b}(t) V_{a d s}\right] d \ln t
$$

Unfortunately, this equation cannot be integrated analytically due to its bulk density dependent term $\rho^{b}$. Therefore, numerical methods are necessary. The standard procedure to solve the system of equations on (Eq. 7) is to sum up the molar fractions in the adsorbed phase and solve for the spreading pressure of the system:

$$
F(\pi)=\sum_{i} \frac{P \varphi_{i} z_{i}^{b}}{f_{i}^{0}(\pi)}-1=0
$$

The initial estimate of the spreading pressure can be obtained with (Eq. 12) by assuming pure component adsorbed phase of the most abundant component in the bulk phase. Newton's method is then used to reach the solution.

$$
\pi^{k+1}=\pi^{k}-\frac{F(\pi)}{F^{\prime}(\pi)}
$$

After solving for $\pi$, the adsorbed phase molar compositions $x_{i}$ are readily obtained by substi- 
tuting the spreading pressure into (Eq. 7), and the excess adsorbed amount can be obtained by applying ideal mixing properties

$$
\sum_{i} \frac{x_{i}}{n_{i}^{0}(\pi)}=\frac{1}{n}
$$

where $n_{i}^{0}$ is the adsorbed amount of component $i$ at spreading pressure $\pi$ in the absence of the other components in the mixture.

To summarize the procedure: First, the pure component experimental data are regressed to an adsorption model. Then, the integral in Eq. 9 is evaluated and inverted for each

component to yield the relation between the fugacity $\left(f^{0}\right)$ and the spreading pressure $(\pi)$. Finally the system of equations in Eq. 7 is solved with respect to the spreading pressure $(\pi)$, which can be subsequently used to compute the excess amounts and molar fractions.

The IAST framework was applied using two different isotherm models fitted to the experimental data for the binary adsorption comparison. One of them is the modified Langmuir in (Eq. 2), and the other is the Toth equation, which is an empirical modification of the Langmuir model to yield improved fitting results.

$$
n^{e x c}=n^{\max }(T) \frac{b(T) f}{\left[1+(b(T) f)^{c}\right]^{\frac{1}{c}}}-\rho^{b} V_{a d s}
$$

where $c$ is a correction exponent parameter. In principle, it is also possible to use the raw experimental data and perform a discrete numerical integration. However, unless the experimental data have low noise and are sufficiently smooth, it is recommended to use analytical fittings of the pure component isotherms as input for the IAST framework.

\section{Multicomponent Potential Adsorption Theory (MPTA)}

The MPTA theory was developed by Shapiro and Stenby ${ }^{19}$ in 1998 for multicomponent mixtures on the basis of the potential concept originally suggested by Polanyi. ${ }^{20}$ The potential theory describes the adsorbate as a distributed fluid inside an external potential field emitted 
by the adsorbent. The properties in the adsorbed phase not only differ from those in the bulk but also depend on the position with respect to the wall. In comparison with ML and IAST, MPTA is a very descriptive model, which can be used to compute other properties besides the adsorbed amounts, such as density, pressure, and composition profiles inside the adsorbed phase. It can also be used to predict the condensation of mixtures close to the wall where the pressure increases notably and can form liquid layers on the wall.

MPTA considers that each component $i$, at any position $z$ from the wall, is at chemical equilibrium with the bulk phase. For a pure component at a constant temperature, the equilibrium between the bulk phase and any point in the adsorbate is given by:

$$
\mu(P(z))-\epsilon(z)=\mu\left(P_{b}\right)
$$

where $\mu$ is the chemical potential, $P(z)$ is the pressure at a distance $z$ from the wall, $\epsilon(z)$ is the potential contribution emitted by the wall, and the subscript $(b)$ refers to the bulk phase. For multicomponent mixtures, Eq. 17 can be extended to:

$$
\mu_{i}(\mathbf{x}(z), P(z))-\epsilon_{i}(z)=\mu_{i}\left(\mathbf{x}_{b}, P_{b}\right)
$$

where $\mathbf{x}$ is the vector of molar fractions $\left(x_{1}, \ldots, x_{N_{c}}\right)$. The solution of Eq. 18 depends on the choice of the EoS to describe fluid properties and the choice of the wall potential function $\epsilon$. In this work, the Peng-Robinson (PR) EoS was used. ${ }^{35}$ The PR EoS is easy to implement and gives satisfactory results for the density of hydrocarbon mixtures, which is an important property used to calculate the adsorbed amount. For the wall, the DubininRadushkevich-Astakhov (DRA) potential was chosen. The DRA potential is an empirical potential introduced by Dubinin ${ }^{28}$ to describe the adsorption of gases on active carbon and it has been successfully applied to different adsorbents and fluids $\left({ }^{24-26}\right)$. It was also applied at high pressures by Monsalvo ${ }^{22}$ obtaining low deviations. The DRA potential has the 
following form:

$$
z(\epsilon)=z_{0} \exp \left[-\left(\frac{\epsilon}{\epsilon_{0}}\right)_{i}^{\beta}\right] \leftrightarrow \epsilon(z)=\epsilon_{0}\left(\ln \frac{z_{0}}{z}\right)^{1 / \beta_{i}}
$$

where $z_{0}$ is common adsorption capacity for all components, $\epsilon_{0, i}$ is the characteristic energy for the solid-fluid interaction, and $\beta_{i}$ the scaling exponent. All three parameters are fitted from pure component experimental data and in principle, are temperature independent. It is worth noting that in the context of DRA, $z$ is treated as the volume of a given pore, and $\epsilon(z)$ as the energy associated to that pore.

In order to solve Eq. 18, only the bulk pressure and composition need to be specified. This is sufficient to determine the properties of the adsorbate at every position or pore volume $z$. This allows us to compute the excess adsorbed amount by integrating the density along $z$ as follows:

$$
\Gamma_{i}=\int_{0}^{z_{0}}\left(\rho_{i}(z) x_{i}(z)-\rho_{b} x_{b, i}\right) d z, \quad \Gamma_{i}=\frac{n_{i}}{A}
$$

where $\Gamma$ is the surface excess and $A$ the surface area of the adsorbent. Immediately, the average composition of the adsorbed amount can be computed as follows:

$$
x_{i}=\frac{\Gamma_{i}}{\sum_{i=1}^{N_{c}} \Gamma_{i}}
$$

The general strategy for solving Eq. 18 is to discretize $z$ (i.e. $z \rightarrow \mathbf{z}=\left\{z^{1}, \ldots, z^{k}, \ldots, \approx 0.1 \AA\right\}$ ) and solve the system point-wise. It is recommended to start far away from the wall $\left(z^{1} \approx z_{0}\right)$, where the adsorbate behaves similarly to the bulk phase. Moreover, the bulk phase properties can be used as initial guess. When the first point is converged, i.e. $P\left(z^{1}\right)$ and $\mathbf{x}\left(z^{1}\right)$ are determined at position $\left(z \approx z_{0}\right)$, a small step is taken towards the wall using the previous point as the initial guess. This procedure is repeated until $z$ reaches an established limit to the wall. The Same procedure can be used to discretize $\epsilon(z)$ instead of $z$. This approach 
avoids coarse intervals in $z$, especially close to the wall, where good resolution is needed for an accurate numerical integration of (Eq. 20).

\section{Experimental data}

Experimental measurements in shale are quite challenging to conduct due to low adsorption capacities, as well as the range of temperature and pressure the experiments are performed under. For instance, adsorption capacity in activated carbon (F400) can be approximately 100 times higher than in shale. ${ }^{6}$ As a result, the relative accuracy of shale measurements becomes lower even without accounting for the challenging temperature and pressure conditions where the measurements are of interest. Gasparik et al. ${ }^{6}$ pointed out these challenges in an inter-laboratory comparison for methane, ethane, and carbon dioxide adsorption measurements at high pressures and temperatures. Although similar standard procedures were used by different laboratories on a shale sample from the same rock, a wide range of results were obtained. Difficulties in the reproducibility of the measurements are observed especially at high pressures, which are the ones of greatest interest for shale reservoir conditions. To obtain more consistent adsorption data in shale at high pressures, standardized methods are needed to have a quality data bank. Despite big efforts are being made to obtain experimental data at high pressures in shale, the data available in literature are still limited, especially for binary systems. Nevertheless, a model comparison is useful to study their capabilities and limitations in the fitting of the pure component isotherms, and the prediction of binary systems.

The tested pure component data contain a total of 55 isotherms for methane, ethane and $\mathrm{CO}_{2}$ and are summarized on Table 1. Even though adsorption data of longer hydrocarbons are of great interest in shale, experimental data at high pressures, to the best of our knowledge, are not available in literature.

Experimental data for adsorption of mixtures in shale available in the literature is very 
Table 1: Experimental data for adsorption of pure components in shale.

\begin{tabular}{cccccc}
\hline Component & $\mathrm{P}(\mathrm{bar})$ & $\mathrm{T}(\mathrm{K})$ & Isotherms & Data points & Source \\
\hline $\mathrm{C}_{1}$ & $0-250$ & $300-473$ & 36 & 484 & $691036-38$ \\
$\mathrm{C}_{2}$ & $0-200$ & $308-368$ & 10 & 180 & $637 *$ \\
$\mathrm{CO}_{2}$ & $0-250$ & $308-358$ & 9 & 186 & 638 \\
\hline
\end{tabular}

* Molecular simulation

limited. Only limited data for binary mixtures can be found. Therefore, we also include the molecular simulation data from ${ }^{37}$ as "experimental" data. In the present work, three systems were tested and are summarized in Table 2.

Table 2: Experimental data for adsorption of binary mixtures in shale.

\begin{tabular}{ccccc}
\hline System & Pressure (bar) & Temperature $(\mathrm{K})$ & Data points & Source \\
\hline $\mathrm{C}_{1}-\mathrm{C}_{2}$ & $0-125$ & $313-333$ & 81 & 36 \\
$\mathrm{C}_{1}-\mathrm{C}_{2}$ & $0-200$ & $308-368$ & 30 & $37 *$ \\
$\mathrm{C}_{1}-\mathrm{CO}_{2}$ & $0-100$ & $308-358$ & 167 & 38 \\
\hline
\end{tabular}

* Molecular simulation

In summary, the data considered are in the range of (0-200 bar) and (308-368 K). Such conditions are relevant for the study of the adsorption process at reservoir conditions. It is worthwhile to mention that not all the pure component data are useful for the predictive calculation for the binary systems. The obtained parameters are shale-specific, meaning that the parameters used for a binary system in certain shale must be regressed from the pure components adsorption isotherms in the same shale.

\section{Comparison of Adsorption Models}

This section summarizes the capability of the three adsorption isotherm models (Langmuir, Toth-Langmuir, and MPTA-DRA) to match the pure component experimental data. Moreover, the predictability of the three multicomponent adsorption models (ML, IAST, and MPTA) to represent the multicomponent experimental data are compared and discussed.

For the pure component experimental data, Figure 2, Figure 3, and Figure 4 show fitting examples of the $\mathrm{C}_{1}, \mathrm{C}_{2}$ and $\mathrm{CO}_{2}$ isotherms, respectively. For the case of $\mathrm{C}_{1}$, Figure 2 shows 
that the MPTA+DRA matches the data slightly better than the other two models. Figure 3 shows that for the $\mathrm{C}_{2}$ case, both MPTA+DRA and Toth match the data quite accurately. Finally, for the $\mathrm{CO}_{2}$ data, Figure 4 shows that Langmuir and Toth match the data better. It is worth mentioning that for components measured in the same shale sample the fitting must be done simultaneously since some parameters, such as the adsorbed volume ( $V_{a d s}$ and $z_{0}$ ), belong to the adsorbent. This might introduce difficulties for pairs of components such as $\mathrm{C}_{1}$ and $\mathrm{CO}_{2}$, since the adsorption of $\mathrm{CO}_{2}$ can be considerably greater than $\mathrm{C}_{1}$ as shown in the three figures.

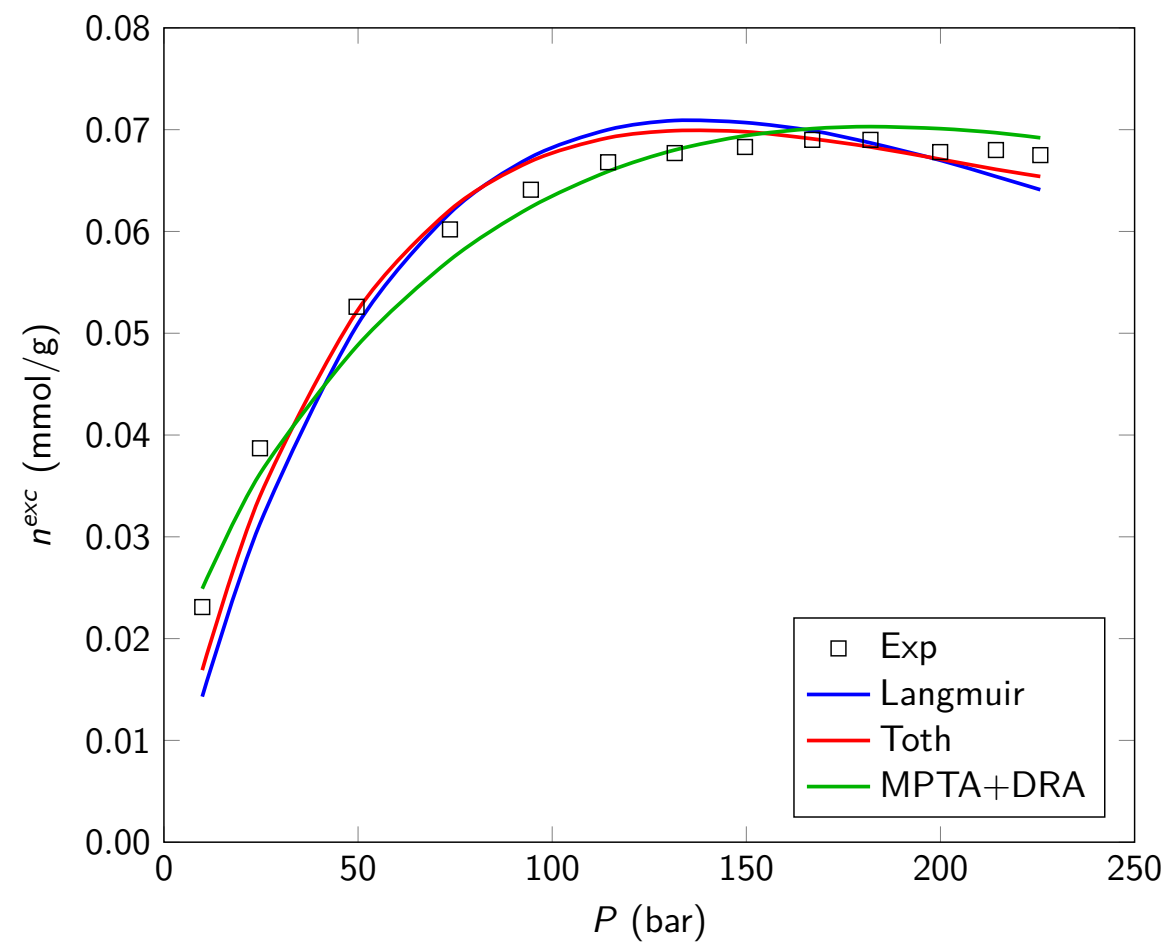

Figure 2: Methane adsorption data fitting example for the three models. Experimental data taken from, ${ }^{6}$ sample "Namurian: Lab $5 " T=338 \mathrm{~K}$

The presented figures are just examples, and obviously, each set of adsorption data will have different results. All the fitting parameters for the considered models are presented as tables in the supporting information. The summarized results for the three models are presented in Table 3, where the Absolute Average Deviation (AAD) is defined as follows: 


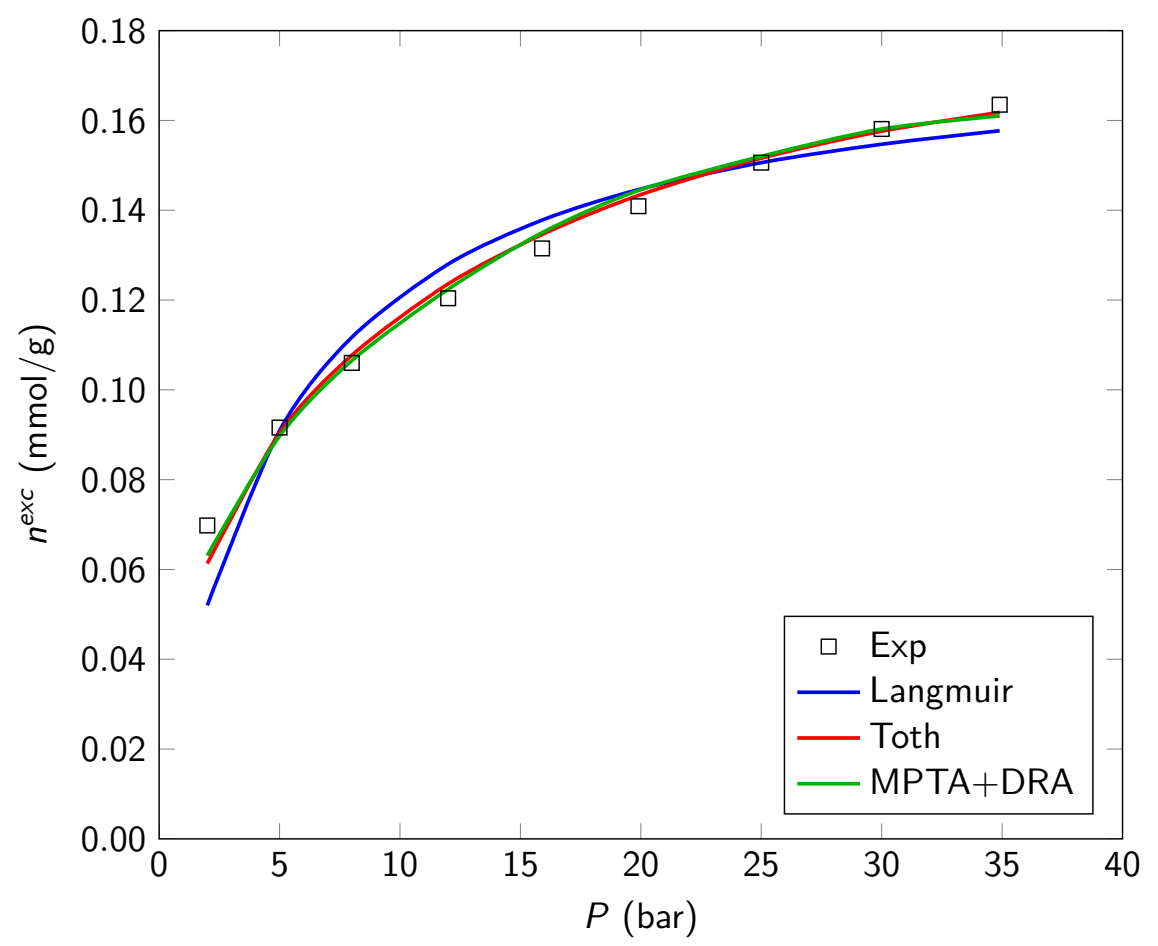

Figure 3: Ethane adsorption data fitting example for the three models. Experimental data taken from. ${ }^{36} \mathrm{~T}=313 \mathrm{~K}$

$$
\operatorname{AAD} \%=\left|\frac{n-n_{e x p}}{n_{e x p}}\right| \times 100 \%
$$

Table 3: Comparison of the three models for pure component adsorption.

\begin{tabular}{|c|c|c|c|c|}
\hline Model & $\begin{array}{l}\text { Parameter } \\
\text { component }\end{array}$ & $\begin{array}{l}\text { type } \\
\text { rock }\end{array}$ & $\begin{array}{c}\text { Total } \\
\text { regressed parameters }\end{array}$ & $\begin{array}{c}\mathrm{AAD} \\
\%\end{array}$ \\
\hline Langmuir & $2^{T}$ & 1 & 119 & 7.78 \\
\hline Toth-Langmuir & $3^{T}$ & 1 & 174 & 5.70 \\
\hline $\mathrm{MPTA}+\mathrm{DRA}$ & 1 & 2 & 65 & 9.12 \\
\hline
\end{tabular}

$T$ Temperature dependent parameter

The lowest deviation is given by the Toth-Langmuir model (Eq. 16). Nevertheless, the difference between the three models is small and the evaluation of the models should take into account other aspects of modeling. MPTA-DRA shows the advantage that the regressed parameters are temperature independent. This considerably reduces the number of parameters when working with different components at different temperatures. Table 3 shows the type of parameters for each model and the total number of parameters fitted for the compar- 


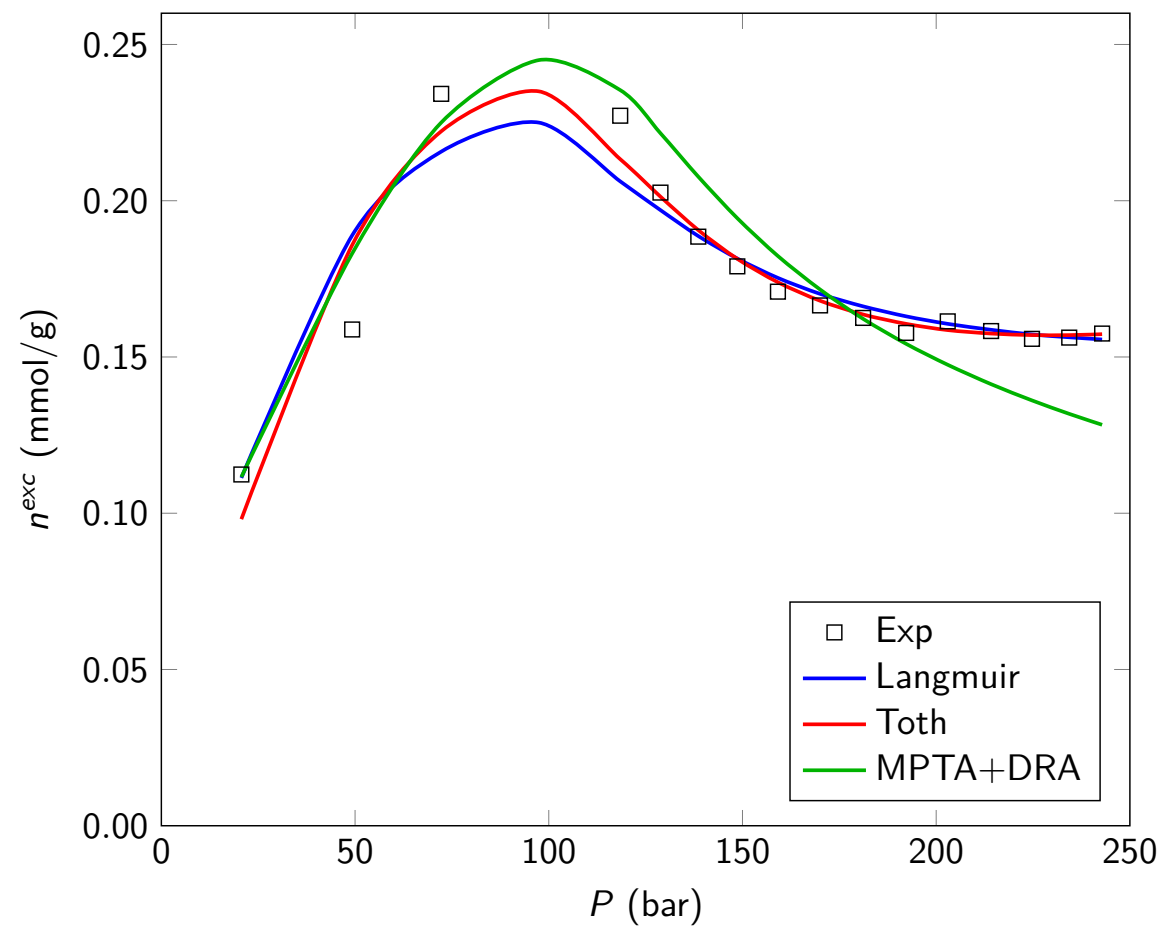

Figure 4: $\mathrm{CO}_{2}$ adsorption data fitting example for the three models. Experimental data taken from, ${ }^{6}$ sample "Namurian: Lab 5 " $T=338 \mathrm{~K}$

ison. In summary, MPTA+DRA has $\left(N_{c}+2\right)$ parameters for each set of isotherms performed in the same sample. The parameters are fewer than those with Langmuir $\left(2 N_{c} \cdot N_{T}+1\right)$ or those with Toth-Langmuir $\left(3 N_{c} \cdot N_{T}+1\right)$, with $N_{c}$ being the number of components and $N_{T}$ the number of measured temperatures.

In principle, the temperature dependent parameters from Langmuir or Toth can be fitted either to empirical correlations or temperature dependent thermodynamic relationships. For instance, the $b$ equilibrium parameter is connected to the enthalpy of adsorption ${ }^{39}$ by the following relationship:

$$
b=\frac{1}{P^{o}} \exp \left(\frac{E_{s}}{R}\right) \exp \left(-\frac{E_{h}}{R T}\right)
$$

where $E_{h}$ is the enthalpy of adsorption and the temperature independent factor $\left\{\frac{1}{P^{o}} \exp \left(\frac{E_{s}}{R}\right)\right\}$ is called the entropic factor. In both cases, for empirical correlations or thermodynamic relationships, we still need to consider additional correlation parameters for the temperature dependence that will introduce an additional error. 
For the mixtures, the AAD in the adsorbed amounts is presented in Table 4. As mentioned in the methodology section, for the IAST framework, the Langmuir and the Toth models were tested for the description of the pure component isotherms. This will allow us to examine if the selection on how to model the isotherms has a big impact on the final results. It is shown that MPTA-DRA has the lowest deviation among the different models, followed by ML and IAST+Langmuir. IAST-Toth gives the highest deviation in spite of the good fitting capabilities for pure component isotherm.

Table 4: Comparison of three models tested for the prediction of the binary adsorption data summarized in Table 2

\begin{tabular}{ccc}
\hline Model & AAD \% & AAD $^{*} \%$ \\
\hline MPTA + DRA & 17.9 & 19.6 \\
IAST + Langmuir & 27.0 & 30.3 \\
IAST + Toth & 31.7 & 35.9 \\
M-Langmuir & 26.1 & 29.1 \\
\hline
\end{tabular}

* Without molecular simulation data from Collell et al. ${ }^{37}$

Figure $6 \mathrm{a}$ and Figure $6 \mathrm{~b}$ show the comparison of the models for a $\mathrm{C}_{1}-\mathrm{C}_{2}$ system. The comparison was made for the adsorbed amounts and also for the selectivity. The selectivity refers to the preference of the adsorbent towards a component with respect to other. It is defined as:

$$
S_{i, j}=\frac{x_{i} / y_{i}}{x_{j} / y_{j}}
$$

where $x_{i}$ is the molar fraction in the adsorbed phase and $y_{i}$ is the molar fraction in the gas phase. In Figure 6a, the adsorbed amounts are equally well represented by all the methods, with a minor deviation for ML at high pressures. One of the reasons for the good prediction of all the models is the ability to fit the underlying pure component isotherms. Figure 5a and Figure 5b show the fitting of the pure component isotherms that were used for the binary prediction. Moreover, differences between the $\mathrm{C}_{1}$ and $\mathrm{C}_{2}$ isotherms, in terms of shape and magnitude of adsorption, are minor. Therefore, one could expect that the behavior of a binary mixture will not be too far from that of the pure components. On the other hand, prediction of the selectivity is not represented as satisfactorily as the adsorbed amounts. 
IAST gives better results for the selectivity towards $\mathrm{C}_{2}$ in the whole pressure range as shown in Figure 6b, while ML shows low deviation at high pressures, and MPTA at low pressures. The predictions in selectivity obtained with MPTA depend on the choice of EoS and wall potential. Adsorption at low pressures is dominated by solid-fluid interactions, where the fluid-fluid interactions are not as important. ${ }^{40}$ An over-prediction of the selectivity at low pressures, may indicate that the potential energy parameter $\epsilon_{0}$ for the $\mathrm{C}_{2}$ is slightly overestimated.

In comparison with the magnitude of adsorption amounts presented in Figure 2 and Figure 3, the ones presented in Figure 6a are notably higher. This is due to the fact that the molecular simulation data used from Collell et al. ${ }^{37}$ is for adsorption in pure kerogen, which is considered the organic matter responsible for the adsorption in shale. Nevertheless, the shape of the adsorption isotherms of shale and pure kerogen are very similar and can be fitted quite accurately in both cases. Similar results are obtained were obtained for the $\mathrm{C}_{1}-\mathrm{C}_{2}$ binary mixtures in Wang et al. ${ }^{36}$ Although figures of the results are not shown here, the prediction of the $\mathrm{C}_{1}-\mathrm{C}_{2}$ binary mixtures at different temperatures and concentrations in Wang et al. ${ }^{36}$ show to be very accurate for the three models. The AAD for all the systems are presented in the supporting information.

Adsorption prediction for binary mixtures containing $\mathrm{CO}_{2}$ does not give results as satisfactory as for the $\mathrm{C}_{1}-\mathrm{C}_{2}$ binary system. Figure $8 \mathrm{a}$ and Figure $8 \mathrm{~b}$ are examples for the predictions of a $\mathrm{C}_{1}-\mathrm{CO}_{2}$ mixture. Despite the deviated fittings of the $\mathrm{C}_{1}$ pure component isotherms, MPTA gives the best prediction among the tested models for the absolute adsorbed amount and also for the individual $\mathrm{CO}_{2}$ adsorbed amount, which suggests that, in order to obtain better predictions in the total adsorbed amount, it is more important to accurately describe the $\mathrm{CO}_{2}$ pure component adsorption isotherm than the $\mathrm{C}_{1}$ isotherm, which has considerable lower adsorption capacity (see Figure 7). It is worth mentioning that this big difference in adsorption capacities between the $\mathrm{CO}_{2}$ and $\mathrm{C}_{1}$ within the same shale sample may be partly attributed to the clay content, and micropore volume $(<2.0 \mathrm{~nm})$ 
of the rock. Adsorption of $\mathrm{CO}_{2}$ has been correlated by Lou and coworkers ${ }^{38}$ with the total clay content for their shale samples used in this work. Furthermore, adsorption of $\mathrm{CO}_{2}$ is enhanced in the micropores due to high energy sites caused by the overlapping of wall potentials that can further stabilized the $\mathrm{CO}_{2}$ molecules. ${ }^{41}$ The clay/kerogen content and the micro-, meso- and macroporous volume of the different shale samples can be found in the supporting information.

In comparison with the $\mathrm{C}_{1}-\mathrm{C}_{2}$ system, all the methods give higher deviations for the $\mathrm{C}_{1}-\mathrm{CO}_{2}$ and none of them are accurate enough. As mentioned previously, the adsorption capacity of $\mathrm{C}_{1}$ with respect $\mathrm{CO}_{2}$ on the same shale rock is considerable lower. The magnitude of the adsorption capacities is in agreement with those reported in simulation data by Psarras and coworkers ${ }^{41}$ (see Figure S1 in Supporting Information). The large differences in $\mathrm{C}_{1}$ and $\mathrm{CO}_{2}$ adsorption capacities introduces difficulties in the simultaneous pure component fitting of $\mathrm{C}_{1}$ and $\mathrm{CO}_{2}$ as presented in Figure $7 \mathrm{a}$ and Figure $7 \mathrm{~b}$. In contrast to the $\mathrm{C}_{1}-\mathrm{C}_{2}$ predictions, mixtures containing $\mathrm{CO}_{2}$ are considerably more difficult. This might be attributed to different reasons. One reason might be that hydrocarbon components are similar to each other, hence the interaction with the shale or kerogen molecules is also similar. Furthermore, its pure adsorption isotherms can be fitted accurately with all the described models, increasing the confidence of a good binary prediction. Another reason is the pressure range of the experiments. For instance, $\mathrm{CO}_{2}$ shows a distinctive behavior after the critical pressures, yielding difficult isotherms for fitting. Therefore, different models must be evaluated in the future for the fitting of pure $\mathrm{CO}_{2}$ data. 


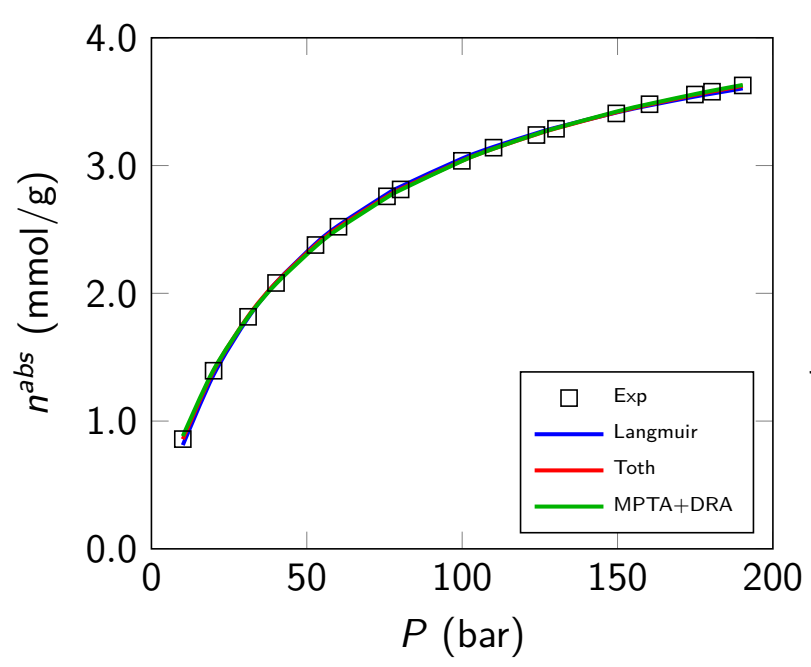

(a) Methane, $\mathrm{C}_{1}$

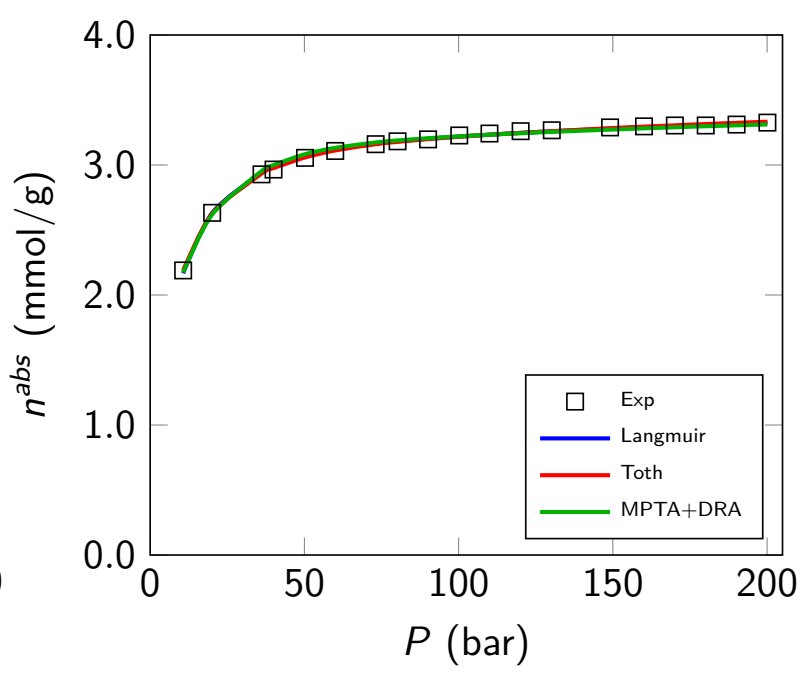

(b) Ethane, $\mathrm{C}_{2}$

Figure 5: Fitting of pure component data used to predict the binary system in Figure 6. Taken from Collell et al. ${ }^{37} T=338 \mathrm{~K}$

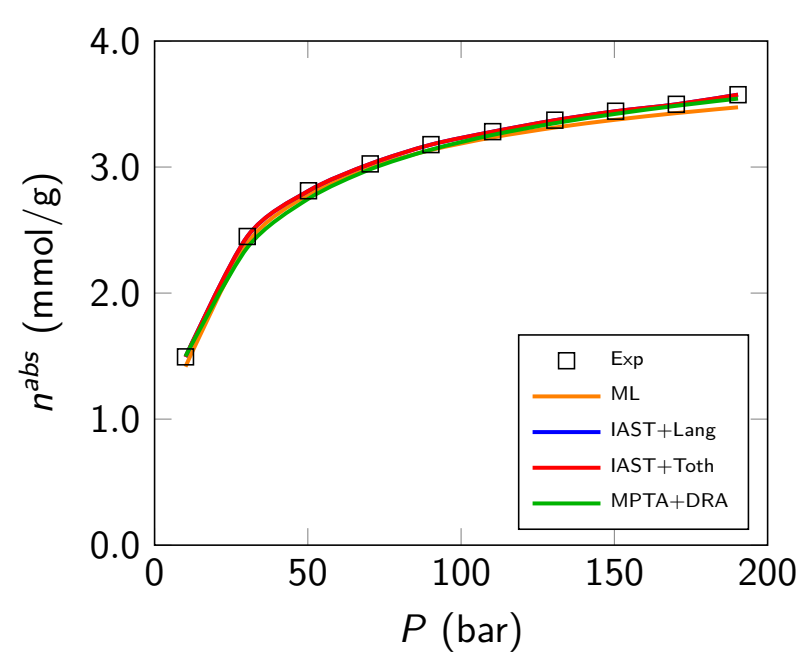

(a) Prediction of adsorbed amounts

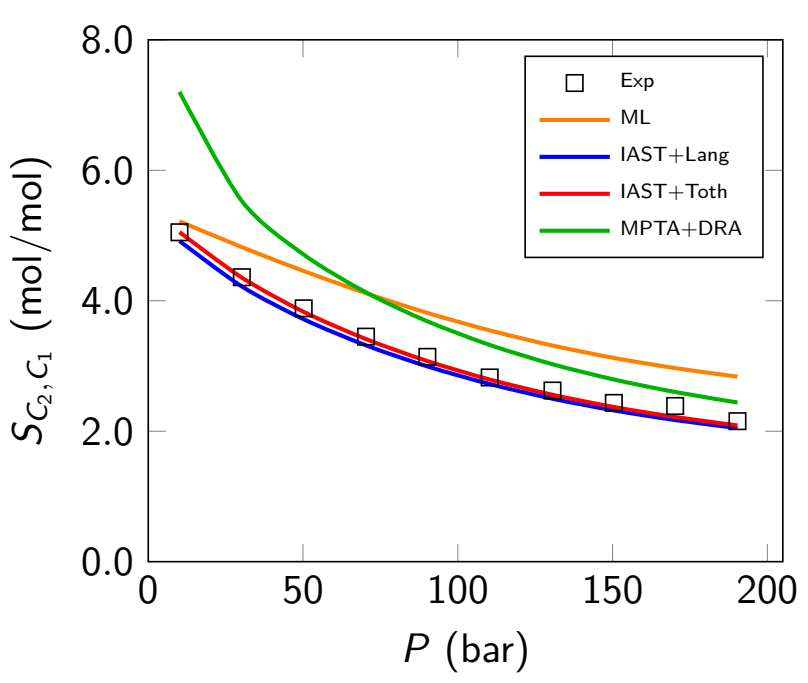

(b) Selectivity of $\mathrm{C}_{2}$ with respect to $\mathrm{C}_{1}$

Figure 6: $\mathrm{C}_{1}-\mathrm{C}_{2}$ mixture with a molar composition of 70\%-30\%. Molecular simulation data taken from Collell et al. ${ }^{37} \mathrm{~T}=338 \mathrm{~K}$ 


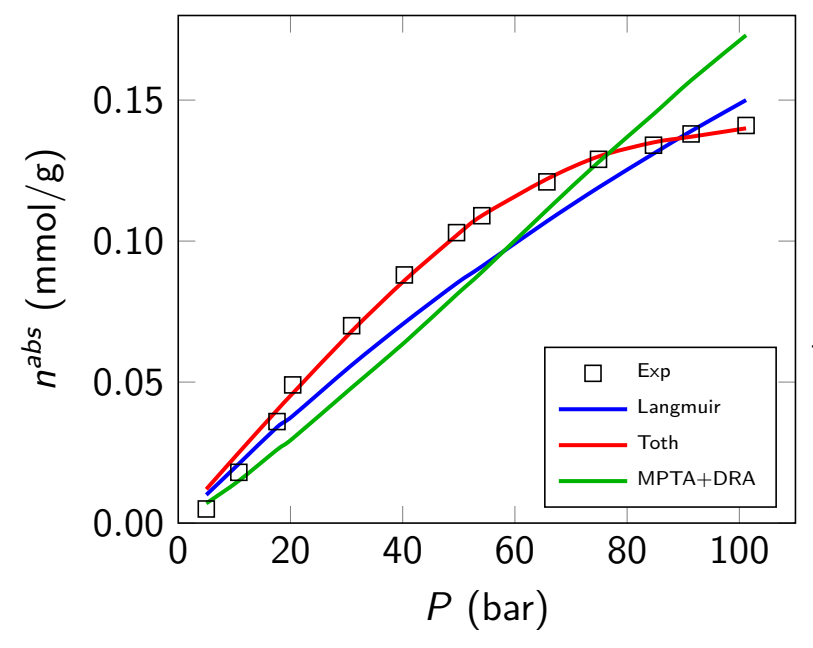

(a) Methane, $\mathrm{C}_{1}$

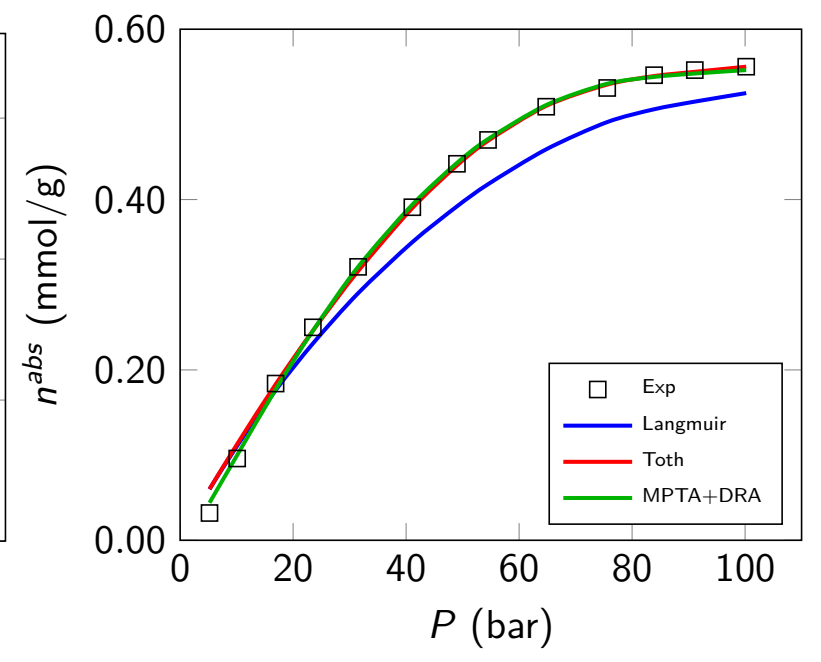

(b) Carbon dioxide, $\mathrm{CO}_{2}$

Figure 7: Fitting of pure component data used to predict the binary system in Figure 8. $T=308 \mathrm{~K}$

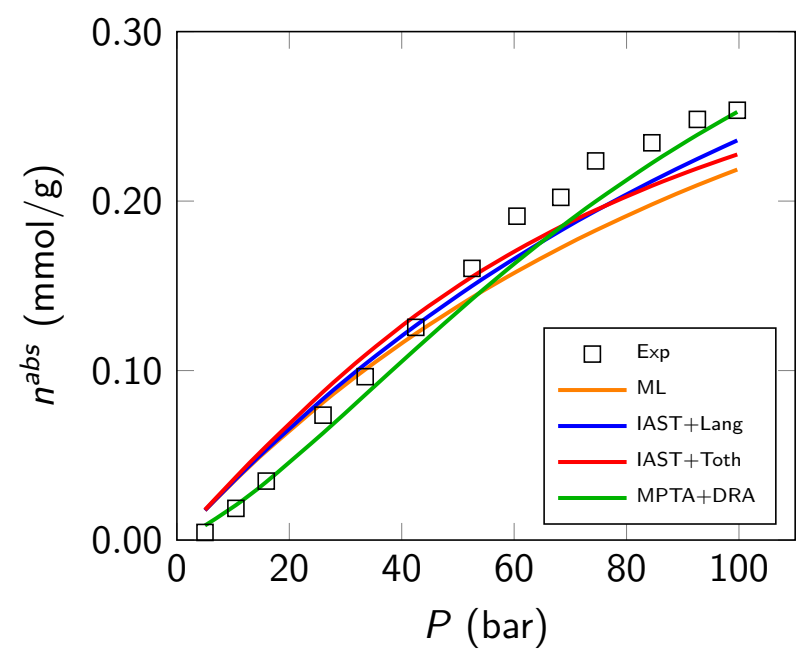

(a) Total adsorbed amount

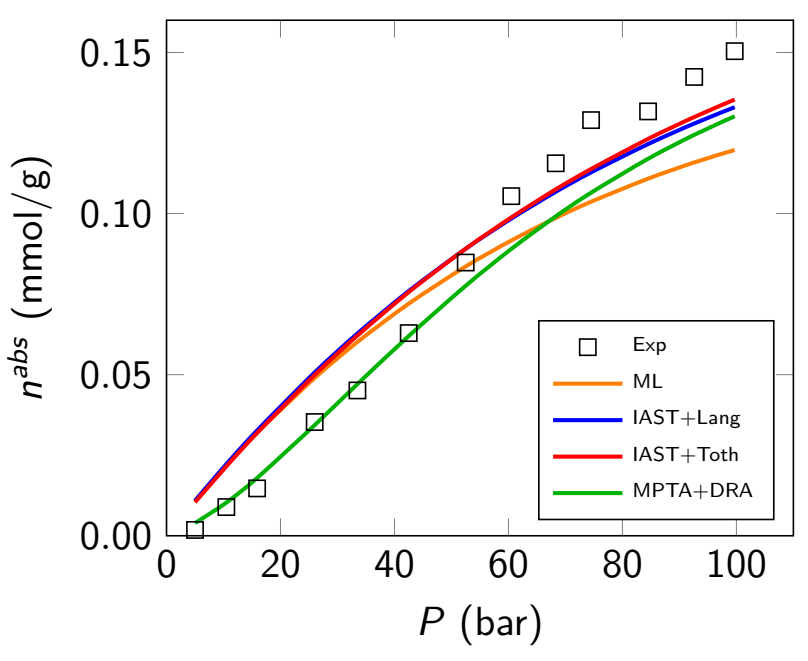

(b) $\mathrm{CO}_{2}$ adsorbed amount

Figure 8: $\mathrm{C}_{1}-\mathrm{CO}_{2}$ mixture with a molar composition of 80\%-20\%. Experimental data taken from Luo et al. (\#1 Shale ${ }^{38}$ ). $T=308 \mathrm{~K}$ 


\section{Influence of Adsorption Film on Phase Behavior}

For a system under a capillary pressure difference, the phase equilibrium changes everywhere except at the critical point. ${ }^{42}$ If we consider an adsorbed phase in the system, its film thickness will reduce the effective capillary radius increasing the pressure difference between the phases as shown by Dong et al. ${ }^{4}$ In order to evaluate the effect of the adsorption film on the phase envelope the following system of equations is solved:

$$
\left\{\begin{array}{l}
\ln K_{i}+\ln F_{i}^{g}\left(T, P_{g}, \mathbf{y}\right)-\ln F_{i}^{l}\left(T, P_{l}, \mathbf{x}\right)=0 ; i=1, \ldots, N_{c} \\
\sum_{i=1}^{N c}\left(y_{i}-x_{i}\right)=0 \\
P_{l}-P_{g}+\frac{2 \sigma \cos \theta}{r_{c}}=0
\end{array}\right.
$$

coupled with:

$$
r_{c}=r-t_{a}
$$

where $K_{i}$ is the equilibrium constant for component $i, T$ is the temperature, $F_{i}$ is the product between the fugacity coefficient $\varphi_{i}$ and its pressure, $P_{l}$ is the pressure in the liquid phase, $P_{g}$ is the pressure in the gas phase, $\sigma$ is the interfacial tension, $r$ is the total radius of the capillary, $r_{c}$ is the effective capillary radius, and $t_{a}$ is the thickness of the adsorption film. The system in (Eq. 25) can be solved for each point of the phase envelope at a given $r_{c}$ by the method presented by Sandoval et al, ${ }^{42}$ which is presented in the supporting information for the reader's convenience. After (Eq. 25) is converged for each $r_{c}$, the thickness $t_{a}$ is then updated in an outer loop. The solution is finally reached by means of successive substitution. The average thickness of the adsorption film is calculated using the following relationship:

$$
t_{a}=\frac{n^{a b s}}{\rho_{a d s} A}
$$

where $n^{a b s}$ is the absolute adsorbed amount, $\rho_{a d s}$ the density in the adsorbed phase, and $A$ is the surface area of the adsorbent. At the saturation point, the density of the adsorbed phase 
is close to the density of the liquid phase $\rho_{l}$ (so-called Gurvich rule ${ }^{43}$ ). The adsorbed amount $n$ is calculated by using the ML and the IAST-Langmuir model. The ML and IAST-Langmuir are easy to implement and the computational cost is low, but has the drawback that the equilibrium parameters $b_{i}$ and $n_{i}^{\max }$ must be known in advance at different temperatures. As already noted, the experimental adsorption data in shale are very limited, making it difficult to apply to the whole range of temperature of the phase envelope. On the other hand, MPTA is computationally expensive, but its model parameters are temperature independent. In principle it can be applied to the whole range of temperature of the phase envelope as a predictive tool.

A solution is proposed here to get both the computational benefit of ML and IAST, and the flexibility of MPTA. MPTA is employed to generate artificial adsorption isotherms at different temperatures. Moreover, it is also used to estimate the adsorption behavior for heavier hydrocarbons where no literature data are available. The detailed procedure for the generation of the ML parameters using MPTA is provided in the supporting information. With adsorption data at different temperatures it is possible to get the temperature dependent Langmuir isotherm parameters for each component.

Three equimolar mixtures of $\mathrm{C}_{1}-\mathrm{C}_{2}, \mathrm{C}_{1}-\mathrm{C}_{4}$ and $\mathrm{C}_{1}-\mathrm{C}_{10}$ inside a capillary tube with a radius of $r=5 \mathrm{~nm}$ are tested and the results are shown in Figure 9, Figure 10, and Figure 11. It can be seen that the adsorption film slightly enhances the effect of the capillary pressure in the phase envelope, especially in the bubble point branch away from the critical point. The calculated adsorption thickness for the three systems along the phase envelope ranges between $0.3 \mathrm{~nm}$ and $1.2 \mathrm{~nm}$, corresponding to approximately one to three times the effective diameter of methane. The adsorption film is more relevant in the bubble point region away from the critical point where the surface tension increases and even a small difference in the effective capillary radius can be of importance. Close to the critical point, the effect of the adsorption film is very small. Near the critical point, the interfacial tension is close to zero corresponding to a very small capillary pressure difference. Therefore, changes 
in the saturation pressure/temperature will be negligible. Moreover, it is important to notice that a small radius of $r_{c}=5 \mathrm{~nm}$ is intentionally selected to test the effect of the adsorption film in an extreme case. For bigger radii, the effect would be even smaller, thus, negligible.

There are many recent theoretical analyses on the phase equilibrium shifts in shale. ${ }^{4,12,18,42,44-48}$ These analyses employ various tools to investigate different aspects of the phase equilibrium shift, such as the phase equilibrium shift under capillary pressure effects by use of an EoS model coupled with the Young-Laplace equation, ${ }^{42,44,48}$ phase behavior and adsorption of pure substances and mixtures in nanopores by DFT, ${ }^{12}$ phase behavior of methane, ethane and their binary mixture in a graphite slab by Grand Canonical Monte Carlo (GCMC) simulations, ${ }^{45}$ and phase envelope generation using shifted critical parameters. ${ }^{4,18,46,47}$ Our analysis on the influence of the adsorption film on the calculated phase envelope is similar to that made by Dong et al., ${ }^{4}$ and both analyses show that the effect of the adsorption film thickness on the phase envelope shift is modest. However, there is one significant difference between the two phase envelope analyses. Dong et al. did not include capillary pressure but assumed that the critical parameters in the EoS model should be changed due to confinement. Our calculation did not take make assumption but included the capillary pressure effects. Due to the shifted model parameters, Dong et al. have obtained significantly shrunk phase envelope compared to ours. There are actually many theoretical studies supporting the shift of critical temperatures and pressures to lower values under nano-confinement. ${ }^{45,49-52}$ But no consensus exists regarding how this should be implemented in a macroscopic thermodynamic model. Obviously, use of shifted parameters in an EoS model is the most convenient way to generate a shifted phase envelope. The theoretical ground for such a treatment is however insufficient. The shifted critical parameters are better considered as a consequence of the wall-fluid interactions rather than a cause. In the DFT study of Li et al., ${ }^{12}$ where shifted critical points for pure components were also obtained, the authors actually commented that the shifted critical properties could not be used in an EoS for the bulk phase with the expectation of correct $\mathrm{P}-\mathrm{T}$ and $\mathrm{T}-\rho$ results in nanopores. 
Among the aforementioned analyses of the phase behavior in porous media, there are studies ${ }^{42,44,48}$ not incorporating the shift in critical points as well as those incorporating the shift. ${ }^{18,46,47}$ The choices may somehow reflect the researchers' perspectives on how to use the developed models in later simulation studies. One implication of using shifted critical parameters is that the EoS using these new parameters is largely sufficient to capture the confinement effect and thus the subsequent simulation study can simply employ the new EoS description. However, the reality may be more complex: Since the flow in the larger pores and fractures of a shale reservoir has to be modeled by the EoS with the original critical parameters, we will have to keep at least two sets of EoS descriptions for essentially two equilibrium regions: one in the bulk phases and another in the nano-pores. Such a phase equilibrium modeling framework is so far unavailable in compositional reservoir simulation to the best of our knowledge. If the dependency of critical parameters on the pore size is considered, the situation will become even more complicated. For those studies not using shifted critical parameters, it is hypothesized that the porous media effects can be largely captured by explicitly accounting for capillary pressure and adsorption in the shale reservoirs. But it should be acknowledged that the shift of critical points in very small pores is missed in these models. More sophisticated theories like DFT and GCMC are more adequate to account for this effect. In order to apply these time consuming tools for analyzing or even simulating macroscopic processes, further simplification is needed.

Finally, it should be mentioned we have considered the validity of the capillary pressure expression and the influence of critical point shift in our selection of pore radius. Fischer and Israelachvili ${ }^{53,54}$ verified the validity of the Kelvin equation experimentally using cyclohexane down to an effective radius of $4 \mathrm{~nm}$. Moreover, the Kelvin equation still remains as a useful theory to characterize mesoporous materials with pore sizes above $10 \mathrm{~nm} .{ }^{55} \mathrm{In}$ our analysis we have chosen $5 \mathrm{~nm}$ as the smallest radius, which should be safe for methane, ethane, and n-butane, and maybe on the threshold for n-decane. At the smallest pore radius (10 $\mathrm{nm}$ in pore diameter), the shifts in critical points for methane and ethane are noticeable 
but relatively modest. ${ }^{45,56}$
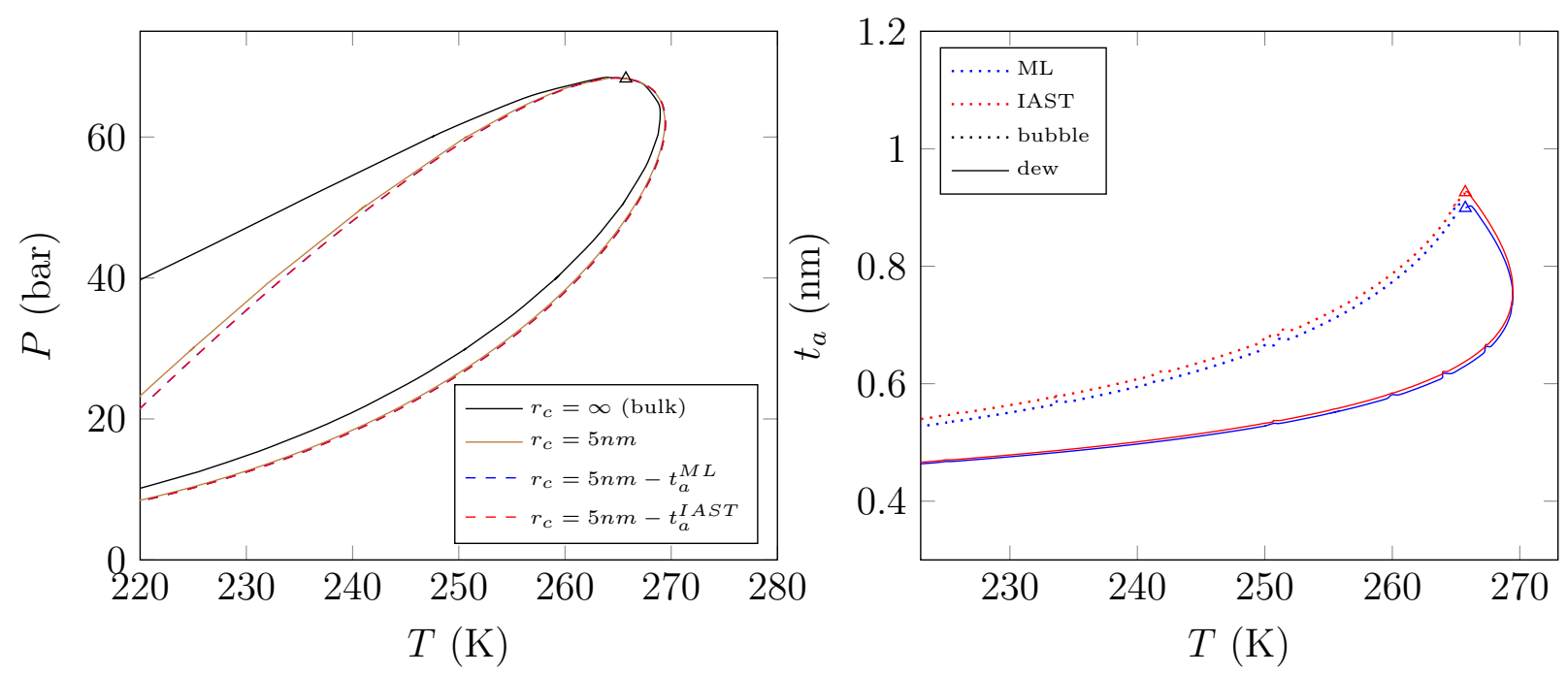

Figure 9: Phase envelope and adsorption thickness for a $\mathrm{C}_{1}-\mathrm{C}_{2}$ equimolar mixture.
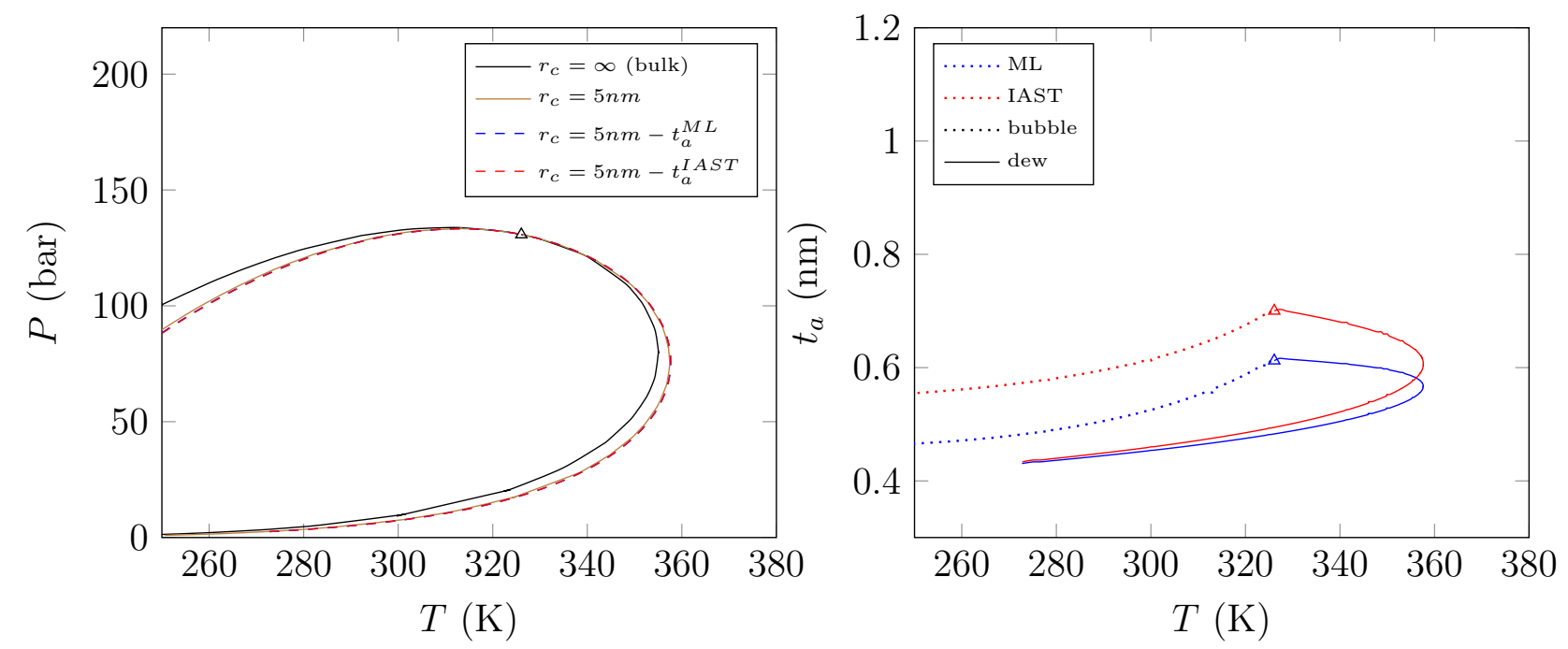

Figure 10: Phase envelope and adsorption thickness for a $\mathrm{C}_{1}-\mathrm{C}_{4}$ equimolar mixture. 

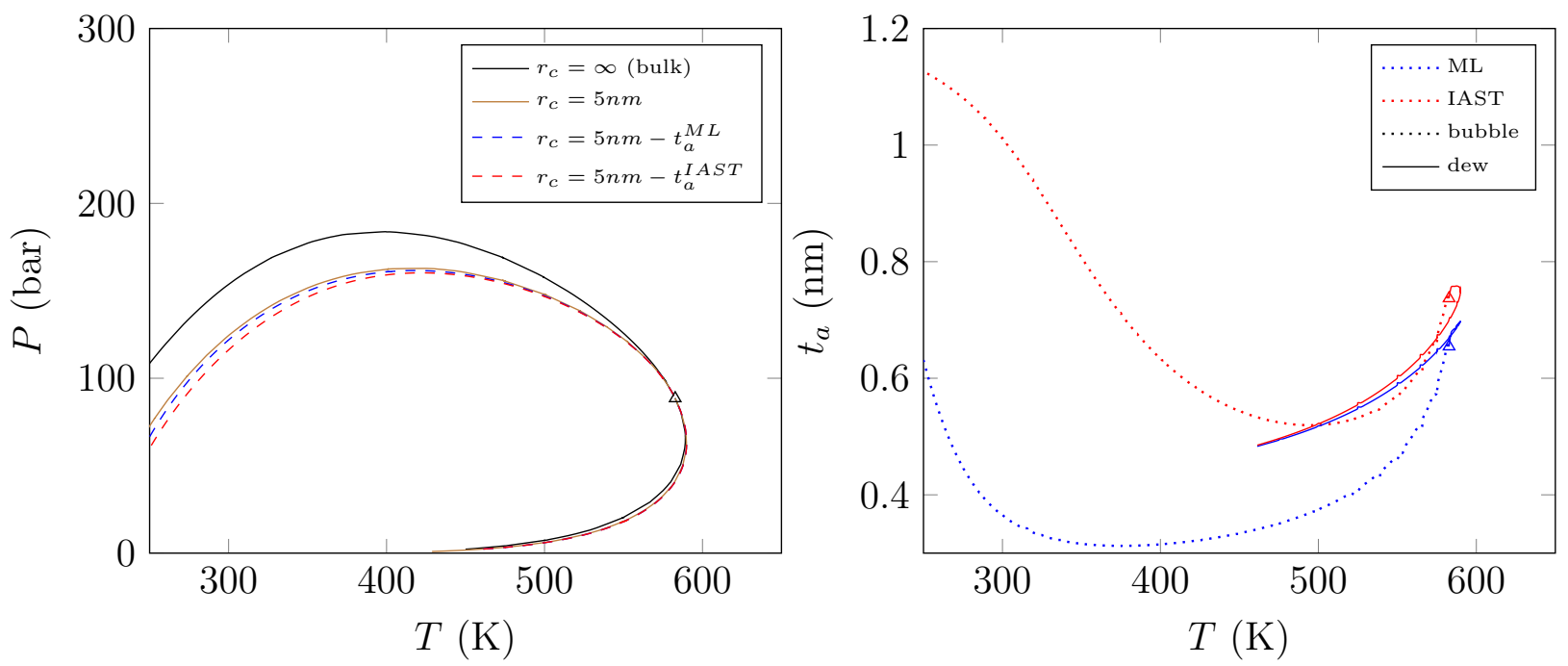

Figure 11: Phase envelope and adsorption thickness for a $\mathrm{C}_{1}-\mathrm{C}_{10}$ equimolar mixture. 


\section{Conclusions}

A model comparison for adsorption of pure components and multicomponent mixtures in shale was presented. Although there are limited experimental data in the literature, the comparison still sheds light on how the tested models perform for shale. Their performance should also be evaluated with the consideration of the number of parameters used, their temperature dependence and the computational cost of these models. It was found that for pure components the Langmuir, Toth, and MPTA-DRA models show comparable results with AADs lower than 10\%. In spite of the computational effort required to fit the pure component adsorption isotherms, MPTA+DRA has much fewer fitting parameters than the Langmuir and Toth models because the parameters in the latter two models are temperature dependent. This makes them less predictive when applying to a wide temperature range where experimental data are not available. This advantage makes MPTA+DRA a more attractive method for describing multiple adsorption isotherms at different temperatures with a total of $N_{c}+2$ parameters.

For binary systems, MPTA+DRA shows the best prediction for the adsorbed amount with an AAD of $17.9 \%$ followed by ML and IAST+Langmuir with $26.1 \%$ and $27.0 \%$, respectively. However, IAST+Langmuir shows a slightly better prediction for the composition in the adsorbed phase. The binary system $\mathrm{C}_{1}-\mathrm{CO}_{2}$ shows to be considerably more challenging than the $\mathrm{C}_{1}-\mathrm{C}_{2}$ system where all the models were able to describe adsorbed amounts and sensitivities quite satisfactorily. One of the reasons may be that the $\mathrm{CO}_{2}$ data at supercritical conditions are difficult to fit with the proposed models. Moreover, the simultaneous fitting of $\mathrm{CO}_{2}$ with a component with considerably lower adsorption capacity such as $\mathrm{C}_{1}$ makes the fitting process even more challenging. Additional modifications in the models, such as component independent adsorption capacities should be considered in future work to improve the results for systems that have noticeable qualitative and quantitative differences in their pure component isotherms. In summary, for the binary mixtures, MPTA+DRA is also preferred due to its better prediction capabilities. However the ML and IAST model, 
in spite of their mathematical simplicity, gives reasonable results and should be considered into account when a simple and fast simulation is required.

In addition, the influence of the adsorption film thickness on the phase behavior was evaluated. We attempted to take advantage of the weak temperature dependency of the MPTA-DRA model parameters and the computational efficiency of ML and IAST in the estimation of the adsorption film thickness along the phase envelope. The adsorption thickness modifies the effective capillary radius inside a porous material enhancing the capillary pressure between the liquid and gas phases. The increase of the capillary pressure becomes relevant in the bubble point branch far away from the critical point where the interfacial tension is higher. The average adsorption film thickness along the phase envelope ranges between $0.3 \mathrm{~nm}$ and $1.2 \mathrm{~nm}$, corresponding to 1-3 layers of methane molecules. The values of the adsorption thickness obtained from ML and IAST do not differ substantially since their predicted total adsorbed amounts are very close to each other.

\section{Supporting Information}

The Supporting Information is available free of charge on the ACS Publication website.

- Additional Details for Adsorption Calculations

- Artificial Adsorption Data from MPTA

- Phase Envelope Calculations with Capillary Pressure

\section{Acknowledgments}

We would like to acknowledge ConocoPhillips and ExxonMobil for their financial support. We are grateful to Prof. Alexander Shapiro for the valuable discussions. 


\section{References}

(1) U.S. Energy Information Administration. Energy Outlook 201\% 2017.

(2) Zhang, T.; Ellis, G. S.; Ruppel, S. C.; Milliken, K.; Yang, R. Effect of OrganicMatter Type and Thermal Maturity on Methane Adsorption in Shale-Gas Systems. Org. Geochem. 2012, 47, 120-131.

(3) Shapiro, A.; Stenby, E. Effects of Capillary Forces and Adsorption on Reserves Distribution (SPE 36922). SPE European Petroleum Conference. Milan, Italy, 1996; pp $441-448$.

(4) Dong, X.; Liu, H.; Hou, J.; Wu, K.; Chen, Z. Phase Equilibria of Confined Fluids in Nanopores of Tight and Shale Rocks Considering the Effect of Capillary Pressure and Adsorption Film. Ind. Eng. Chem. Res. 2016, 55, 798-811.

(5) Loucks, R. G.; Reed, R. M.; Ruppel, S. C.; Jarvie, D. M. Morphology, Genesis, and Distribution of Nanometer-Scale Pores in Siliceous Mudstones of the Mississippian Barnett Shale. J. Sediment. Res. 2009, 79, 848-861.

(6) Gasparik, M.; Rexer, T.; Aplin, A.; Billemont, P.; De Weireld, G.; Gensterblum, Y.; Henry, M.; Krooss, B.; Liu, S; Ma, X.; Sakurovs, R.; Song, Z.; Staib, G.; Thomas, K. M.; Wang, S.; Zhang, T. First International Inter-Laboratory Comparison of High-Pressure $\mathrm{CH}_{4}, \mathrm{CO}_{2}$ and $\mathrm{C}_{2} \mathrm{H}_{6}$ Sorption Isotherms on Carbonaceous Shales. Int. J. Coal Geol. 2014, 132, 131-146.

(7) Holmes, R.; Rupp, E. C.; Vishal, V.; Wilcox, J. Selection of Shale Preparation Protocol and Outgas Procedures for Applications in Low-Pressure Analysis. Energy Fuels 2017, 31, 9043-9051.

(8) Gasparik, M.; Ghanizadeh, A.; Bertier, P.; Gensterblum, Y.; Bouw, S.; Krooss, B. M. 
High-Pressure Methane Sorption Isotherms of Black Shales from the Netherlands. Energy Fuels 2012, 26, 4995-5004.

(9) Rexer, T. F.; Benham, M. J.; Aplin, A. C.; Thomas, K. M. Methane Adsorption on Shale under Simulated Geological Temperature and Pressure Conditions. Energy Fuels 2013, 27, 3099-3109.

(10) Rexer, T. F.; Mathia, E. J.; Aplin, A. C.; Thomas, K. M. High-Pressure Methane Adsorption and Characterization of Pores in Posidonia Shales and Isolated Kerogens. Energy Fuels 2014, 28, 2886-2901.

(11) Myers, A. L.; Prausnitz, J. M. Thermodynamics of Mixed-Gas Adsorption. AIChE J. $1965,11,121-127$.

(12) Li, Z.; Jin, Z.; Firoozabadi, A. Phase Behavior and Adsorption of Pure Substances and Mixtures and Characterization in Nanopore Structures by Density Functional Theory (SPE SPE-169819-PA). SPE J. 2014, 19, 1096-1109.

(13) Rangarajan, B.; Lira, C. T.; Subramanian, R. Simplified Local Density Model for Adsorption over Large Pressure Ranges. AIChE J. 1995, 41, 838-845.

(14) Fitzgerald, J. E. Adsorption of Pure and Multicomponent Gases of Importance to Enhanced Coalbed Methane Recovery: Measurements and Simplified Local Density Modeling. Ph.D. Dissertation, Oklahoma State University, Stillwater, OK, 2005.

(15) Fitzgerald, J. E.; Robinson, R. L.; Gasem, K. A. Modeling High-Pressure Adsorption of Gas Mixtures on Activated Carbon and Coal Using a Simplified Local-Density Model. Langmuir 2006, 22, 9610-9618.

(16) Mohammad, S. A.; Chen, J. S.; Robinson, R. L.; Gasem, K. A. Generalized Simplified Local-Density/Peng-Robinson Model for Adsorption of Pure and Mixed Gases on Coals. Energy Fuels 2009, 23, 6259-6271. 
(17) Chareonsuppanimit, P.; Mohammad, S. A.; Robinson, R. L.; Gasem, K. A. M. HighPressure Adsorption of Gases on Shales: Measurements and Modeling. Int. J. Coal Geol. 2012, 95, 34-46.

(18) Ma, Y.; Jamili, A. Using Simplified Local Density/ Peng-Robinson Equation of State to Study the Effects of Confinement in Shale Formations on Phase Behavior (SPE 168986). SPE Unconventional Resources Conference. The Woodlands, Texas, USA, 2014; pp 114.

(19) Shapiro, A.; Stenby, E. Potential Theory of Multicomponent Adsorption. J. Colloid Interface Sci. 1998, 15\%, 146-157.

(20) Polanyi, M. Potential Theory of Adsorption. Verh. Disch. Phys. Ges. 1914, 16, 1012.

(21) Bae, J. S.; Bhatia, S. K. High-Pressure Adsorption of Methane and Carbon Dioxide on Coal. Energy Fuels 2006, 20, 2599-2607.

(22) Monsalvo, M.; Shapiro, A. Study of High-Pressure Adsorption from Supercritical Fluids by the Potential Theory. Fluid Phase Equilib. 2009, 283, 56-64.

(23) Chilev, C.; Darkrim Lamari, F.; Kirilova, E.; Pentchev, I. Comparison of Gas Excess Adsorption Models and High Pressure Experimental Validation. Chem. Eng. Res. Des. 2012, 90, 2002-2012.

(24) Monsalvo, M.; Shapiro, A. Modeling Adsorption of Binary and Ternary Mixtures on Microporous Media. Fluid Phase Equilib. 2007, 254, 91-100.

(25) Monsalvo, M.; Shapiro, A. Modeling Adsorption of Liquid Mixtures on Porous Materials. J. Colloid Interface Sci. 2009, 333, 310-6.

(26) Bartholdy, S.; Bjørner, M. G.; Solbraa, E.; Shapiro, A.; Kontogeorgis, G. M. Capabilities and Limitations of Predictive Engineering Theories for Multicomponent Adsorption. Ind. Eng. Chem. Res. 2013, 52, 11552-11563. 
(27) Clarkson, C. R.; Haghshenas, B. Modeling of Supercritical Fluid Adsorption on Organic-Rich Shales and Coal (SPE 164532). SPE Unconventional Resources Conference. The Woodlands, Texas, USA, 2013; pp 1-24.

(28) Dubinin, M. M. Microporous Structures and Absorption Properties of Carbonaceous Adsorbents. Carbon 1983, 21, 359-366.

(29) Zhou, C.; Hall, F.; Gasem, K. A. M.; Robinson, R. L. J. Predicting Gas Adsorption Using Two-Dimensional Equations of State. Ind. Eng. Chem. Res. 1994, 33, 1280-1289.

(30) Langmuir, I. The Adsorption of Gases on Plane Surfaces of Glass, Mica and Platinum. J. Am. Chem. Soc. 1918, 40, 1361-1403.

(31) Adamson, A. W.; Gast, A. P. Physical Chemistry of Surfaces, 6th ed.; Wiley \& Sons, Inc: United States of America, 1997.

(32) Defay, R.; Prigogine, I.; Bellemans, A.; Everett, D. H. Surface Tension and Adsorption; Longmans, Green \& Co Ltd: London W1, 1966.

(33) Myers, A. L. Thermodynamics of Adsorption in Porous Materials. AIChE J. 2002, 48, $145-160$.

(34) Mitchell, L. A.; LeVan, M. D. Development of Adsorption Equilibrium Relations for Mixtures from Pure Component Isotherms and Henry's Law Behavior with Components in Excess. Ind. Eng. Chem. Res. 2014, 53, 15531-15537.

(35) Peng, D.-Y.; Robinson, D. B. A New Two-Constant Equation of State. Ind. Eng. Chem. Fund. 1976, 15, 59-64.

(36) Wang, Y.; Tsotsis, T. T.; Jessen, K. Competitive Sorption of Methane/Ethane Mixtures on Shale: Measurements and Modeling. Ind. Eng. Chem. Res. 2015, 54, 12187-12195.

(37) Collell, J.; Galliero, G.; Gouth, F.; Montel, F.; Pujol, M.; Ungerer, P.; Yiannourakou, M. Molecular Simulation and Modelisation of Methane/Ethane Mixtures Adsorption onto 
a Microporous Molecular Model of Kerogen under Typical Reservoir Conditions. Microporous Mesoporous Mater. 2014, 197, 194-203.

(38) Luo, X.; Wang, S.; Wang, Z.; Jing, Z.; Lv, M.; Zhai, Z.; Han, T. Adsorption of Methane, Carbon Dioxide and Their Binary Mixtures on Jurassic Shale from the Qaidam Basin in China. Int. J. Coal Geol. 2015, 150-151, 210-223.

(39) Myers, A.; Monson, P. Adsorption in Porous Materials at High Pressure: Theory and Experiment. Langmuir 2002, 18, 10261-10273.

(40) Thommes, M. Physical Adsorption Characterization of Nanoporous Materials. ChemieIngenieur-Technik 2010, 82, 1059-1073.

(41) Psarras, P.; Holmes, R.; Vishal, V.; Wilcox, J. Methane and $\mathrm{CO}_{2}$ Adsorption Capacities of Kerogen in the Eagle Ford Shale from Molecular Simulation. Acc. Chem. Res. 2017, $50,1818-1828$.

(42) Sandoval, D. R.; Yan, W.; Michelsen, M. L.; Stenby, E. H. The Phase Envelope of Multicomponent Mixtures in the Presence of a Capillary Pressure Difference. Ind. Eng. Chem. Res. 2016, 55, 6530-6538.

(43) Gurvich, L. G. Physico-Chemical Force of Attraction. J. Phys. Chem. Soc. Russ. 1915, $47,805-827$.

(44) Pang, J.; Zuo, J.; Zhang, D.; Du, L.; Corporation, H. Effect of Porous Media on Saturation Pressures of Shale Gas and Shale Oil (IPTC 16419). International Petroleum Technology Conference. Beijing, China, 2013; pp 1-7.

(45) Pitakbunkate, T.; Balbuena, P. B.; Moridis, G. J.; Blasingame, T. A. Effect of Confinement on Pressure/Volume/Temperature Properties of Hydrocarbons in Shale Reservoirs (SPE SPE-170685-PA). SPE J. 2016, 21, 621-634. 
(46) Devegowda, D.; Sapmanee, K.; Civan, F.; Sigal, R. Phase Behavior of Gas Condensates in Shales Due to Pore Proximity Effects: Implications for Transport, Reserves and Well Productivity (SPE 160099). SPE Annual Technical Conference and Exhibition. San Antonio, Texas, USA, 2012; pp 4197-4218.

(47) Clarkson, C. R.; Haghshenas, B. Characterization of Multi-Fractured Horizontal Shale Wells Using Drill Cuttings: 1. Fluid-in-Place Estimation. J. Nat. Gas Sci. Eng. 2016, 32, 574-585.

(48) Nojabaei, B.; Johns, R. T.; Chu, L. Effect of Capillary Pressure on Phase Behavior in Tight Rocks and Shales. SPE Reserv. Eval. Eng. 2013, August, 281-289.

(49) Zarragoicoechea, G.; Kuz, V. Van der Waals Equation of State for a Fluid in a Nanopore. Phys. Rev. E: Stat. Phys., Plasmas, Fluids 2002, 65, 021110.

(50) Zarragoicoechea, G. J.; Kuz, V. a. Critical Shift of a Confined Fluid in a Nanopore. Fluid Phase Equilib. 2004, 220, 7-9.

(51) Singh, S. K.; Sinha, A.; Deo, G.; Singh, J. K. Vapor - Liquid Phase Coexistence, Critical Properties, and Surface Tension of Confined Alkanes. J. Phyis. Chem. C 2009, 113, $7170-7180$.

(52) Travalloni, L.; Castier, M.; Tavares, F. W.; Sandler, S. I. Thermodynamic Modeling of Confined Fluids Using an Extension of the Generalized Van der Waals Theory. Chem. Eng. Sci. 2010, 65, 3088-3099.

(53) Fisher, L.; Israelachvili, J. Direct Experimental Verification of the Kelvin Equation for Capillary Condensation. Nature 1979, 277, 548-549.

(54) Fisher, L.; Israelachvili, J. Direct Measurement of the Effect of Meniscus Forces on Adhesion: A Study of the Applicability of Macroscopic Thermodynamics to Microscopic Liquid Interfaces. Colloids Surf. 1981, 3, 303 - 319. 
(55) Barrett, E. P.; Joyner, L. G.; Halenda, P. P. The Determination of Pore Volume and Area Distributions in Porous Substances. I. Computations from Nitrogen Isotherms. J. Am. Chem. Soc. 1951, 73, 373-380.

(56) Pitakbunkate, T.; Blasingame, T. A.; Moridis, G. J.; Balbuena, P. B. Phase Behavior of Methane-Ethane Mixtures in Nanopores. Ind. Eng. Chem. Res. 2017, 56, 11634-11643. 


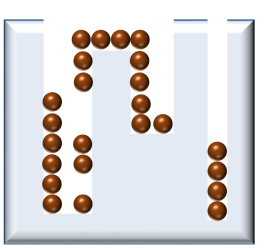

(a) Langmuir

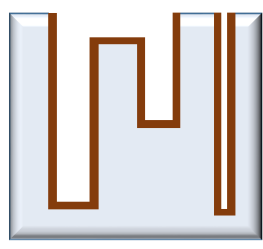

(b) IAST

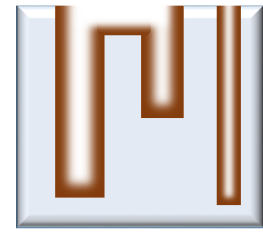

(c) MPTA

For Table of Contents Only 